\title{
The $5-\mathrm{HT}_{7}$ receptor is involved in allocentric spatial memory information processing
}

\author{
Gor Sarkisyan and Peter B. Hedlund \\ Department of Molecular Biology, The Scripps Research Institute, La Jolla, California
}

\begin{abstract}
The hippocampus has been implicated in aspects of spatial memory. Its ability to generate new neurons has been suggested to play a role in memory formation. Hippocampal serotonin (5-HT) neurotransmission has also been proposed as a contributor to memory processing. Studies have shown that the $5-\mathrm{HT}_{7}$ receptor is present in the hippocampus in relatively high abundance. Thus the aim of the present study was to investigate the possible role of the $5-\mathrm{HT}_{7}$ receptor in spatial memory using 5- $\mathrm{HT}_{7}$ receptor-deficient mice $\left(5-\mathrm{HT}_{7}{ }^{-/-}\right)$. A hippocampus-associated spatial memory deficit in 5$\mathrm{HT}_{7}{ }^{-/-}$mice was demonstrated using a novel location/novel object test. A similar reduction in novel location exploration was observed in $\mathrm{C} 57 \mathrm{BL} / 6 \mathrm{~J}$ mice treated with the selective $5-\mathrm{HT}_{7}$ receptor antagonist SB-269970. These findings prompted an extended analysis using the Barnes maze demonstrating that $5-\mathrm{HT}_{7}^{-/-}$mice were less efficient in accommodating to changes in spatial arrangement than $5-\mathrm{HT}_{7}^{+/+}$mice. $5-\mathrm{HT}_{7}{ }^{-/-}$mice had specific impairments in memory compilation required for resolving spatial tasks, which resulted in impaired allocentric spatial memory whereas egocentric spatial memory remained intact after the mice were forced to switch back from striatumdependent egocentric to hippocampus-dependent allocentric memory. To further investigate the physiological bases underlining these behaviors we compared hippocampal neurogenesis in 5$\mathrm{HT}_{7}^{+/+}$and $5-\mathrm{HT}_{7}{ }^{-/-}$mice employing BrdU immunohistochemistry. The rate of cell proliferation in the dentate gyrus was identical in the two genotypes. From the current data we conclude that the 5$\mathrm{HT}_{7}{ }^{-/}$mice performed by remembering a simple sequence of actions that resulted in successfully locating a hidden target in a static environment.
\end{abstract}

\section{Keywords}

serotonin; Barnes maze; neurogenesis; novel location; novel object; allocentric; exocentric; egocentric

\section{Introduction}

Neuropsychological studies have shown that several brain regions including the medial temporal lobe [1], the hippocampus [2,3], the parietal cortex [4-6], and the striatum [7-9] are involved in spatial memory processing. Spatial memory is the ability to code, store and retrieve information about spatial layouts in the environment, thus enabling the learning of a path

Corresponding Author: Peter B. Hedlund, MD, PhD, Department of Molecular Biology, MB10, The Scripps Research Institute, 10550 North Torrey Pines Road, La Jolla, CA 92037, Telephone: 858-784-8565, Facsimile: 858-784-2212, Email: E-mail: hedlund@scripps.edu.

Publisher's Disclaimer: This is a PDF file of an unedited manuscript that has been accepted for publication. As a service to our customers we are providing this early version of the manuscript. The manuscript will undergo copyediting, typesetting, and review of the resulting proof before it is published in its final citable form. Please note that during the production process errors may be discovered which could affect the content, and all legal disclaimers that apply to the journal pertain. 
between two points or remembering the location of objects. Several, more or less independent, components of spatial memory have been identified. Thus, procedural spatial learning (route learning) can be distinguished from declarative spatial memory (object location memory) [10]. Declarative spatial memory can be further subdivided into memory of the position of objects or stimuli that is independent of the observer (allocentric spatial memory) and memory that is in relation to the observer (egocentric spatial memory) [11]. Specifically, the dorsal and lateral striatum is involved in processing egocentric memory [12,13,7], and the hippocampus on the other hand is involved in allocentric spatial memory processing [14].

In animal studies, it has been demonstrated that the hippocampus is critical for the formation of spatial and contextual fear memories [15]. Intact immediate memory and abnormally rapid loss of spatial memory has been observed in animals with damage limited to the hippocampus [16] whereas memories acquired prior to the lesions remained intact. In rodents, hippocampal damage leads to reduced performance in the Morris water maze when the animal is placed at different positions in the maze for each trial (allocentric memory) [14] but not when placed at the same initial starting point for each trial (egocentric memory) [17]. Furthermore, aversive stimuli, such as foot shock, known to induce anxiety, depression, and fear memory, have been shown to also alter activity-dependent hippocampal synaptic plasticity [18-20]. The role of hippocampal region in initial formation of memories and its relay to a final storage in other parts of the brain has also been described in humans [21-24].

5-hydroxytryptamine (serotonin, 5-HT) can alter synaptic plasticity as demonstrated in studies of long-term potentiation (LTP) and depression (LTD) $[25,26]$. Thus, it is possible that perturbations of 5-HT neurotransmission might affect hippocampus-dependent learning and memory. 5-HT exerts its action by interacting with at least 14 different receptor subtypes [27]. The 5-HT 7 receptor is one of the most recently discovered 5-HT receptors. It is a G protein-coupled receptor positively coupled to adenylyl cyclase. The highest density of 5$\mathrm{HT}_{7}$ receptor expression has been described in the thalamus, hippocampus, and frontal cortex $[57,58,59]$. A role for the $5-\mathrm{HT}_{7}$ receptor has been suggested in several physiological and pathophysiological phenomena, including memory formation and/or consolidation, depression, obsessive-compulsive disorder, circadian rhythm regulation, and sleep disorders [31]. Interestingly, it has been shown that mice lacking the $5-\mathrm{HT}_{7}$ receptor show a selective impairment in contextual fear conditioning [32]. Furthermore, there was a reduced ability to induce LTP in hippocampal slices from these mice [32]. These findings suggest a role of the $5-\mathrm{HT}_{7}$ receptor in hippocampal function. Additionally, selective $5-\mathrm{HT}_{7}$ receptor antagonist SB-269970 influences hippocampus-dependent learning [33].

A unique feature of the hippocampus is its ability to generate new neurons even in adulthood. It has been shown that the newly born neurons become synaptically active [34]. Based on these and other studies [35,36], a putative link between adult neurogenesis and hippocampal functions have been made, especially a link with learning and memory [37].

In order to further study the possible involvement of $5-\mathrm{HT}_{7}$ receptors in hippocampal function we have employed behavioral models to assess hippocampus-dependent learning and memory, and investigated hippocampal neurogenesis in $5-\mathrm{HT}_{7}$-receptor deficient mice. It was hypothesized that pharmacological blockage or inactivation of $5-\mathrm{HT}_{7}$ receptor might result in impairments in the ability of mice to correctly integrate and/or utilize information regarding their environment resulting in difficulties to cope with spatial changes. 


\section{Materials and methods}

\subsection{Animals}

Most experiments were performed using male $5-\mathrm{HT}_{7}{ }^{-/-}$mice and their male $5-\mathrm{HT}_{7}{ }^{+/+}$siblings as controls. The generation of the $5-\mathrm{HT}_{7}^{-/-}$mouse strain has been described previously [38]. Briefly, the 5- $\mathrm{HT}_{7}{ }^{-/}$mice were created by a targeted disruption within exon II of the 5- $\mathrm{HT}_{7}$ receptor gene, thus inactivating all known splice variants of the receptor protein. The inactivation was done in embryonic stem cells derived from 129Sv mice followed by breeding with C57BL/6J mice. The mice used in this study had been backcrossed on the C57BL/6J background for at least 16 generations.

All mice were housed in a 12-hour light/dark cycle (lights on at 0600 and off at 1800) and had free access to water and food pellets. For the behavioral experiments 10 to 12 week-old mice were used. Since hippocampal neurogenesis is highly age-dependent [39], the animals used for this part of the study were exactly 90 days because these animals are still relatively young, but the rate of neurogenesis is slightly reduced resulting in more accurate assessment of BrdU incorporation. With a higher rate of neurogenesis, it becomes difficult to accurately differentiate between BrdU positive cells in close proximity.

All the experiments were carried out in accordance with the Guide for the Care and Use of Laboratory Animals as adopted and promulgated by the US National Institutes of Health and were approved by the Animal Care and Use Committee at The Scripps Research Institute. Every effort was made to reduce the number of animals used and to minimize potential suffering. In total, 61 mice were used for the present study. The novel location/novel object test was performed using $95-\mathrm{HT}_{7}^{-/-}$mice, $85-\mathrm{HT}_{7}{ }^{+/+}$mice, and $20 \mathrm{C} 57 \mathrm{BL} / 6 \mathrm{~J}$ mice for the drug treatment part. The Barnes maze experiment was conducted using $85-\mathrm{HT}_{7}{ }^{-/-}$mice and $85-$ $\mathrm{HT}_{7}^{+/+}$mice. For the neurogenesis experiment $45-\mathrm{HT}_{7}{ }^{-/-}$mice and $45-\mathrm{HT}_{7}^{+/+}$mice were used.

\subsection{Novel location/Novel object test}

The novel object recognition test was adapted from a procedure published by Benice and colleagues [40]. For three consecutive days, the mice were individually habituated to a 43.5 $\mathrm{cm} \times 43.5 \mathrm{~cm} \times 22.5 \mathrm{~cm}$ square open field with Plexiglas walls for $5 \mathrm{~min}$. On the fourth day, the mice were trained in three consecutive 5-min familiarization trials, and then tested in two consecutive 5-min trials, each with a $1 \mathrm{~min}$ inter-trial interval. For the familiarization trials, three plastic toy objects were placed in the corners of the open field. An individual mouse was placed in the center of the field facing the same direction in each trial and allowed to explore for $5 \mathrm{~min}$. The location of the objects was kept constant between trials and animals. All familiar objects were exchanged with replicas in subsequent trials. After the three familiarization trials, the mice were tested in a location novelty recognition test in which one of the familiar objects was moved to an adjacent, vacant corner of the stage. The same object was moved to the same new location for every mouse tested. The mouse was then tested in an object novelty recognition test in which a novel object replaced one of the familiar objects. The four day behavioral test was conducted only once per animal. All objects and the arena were thoroughly cleaned with $70 \%$ ethanol between trials to remove odors.

The four different objects required for this study were chosen based on there being no statistically significant preference for any object in previous studies using C57BL/6J mice [41] and included a toy man, woman, horse, and cow (Playmobil, Geobra Brandstatter GmbH and Co. KG, Zirndorf, Germany). The objects chosen were made of durable non-toxic plastic and of comparable size, approximately $7 \mathrm{~cm}$ tall. Each object was fixed to a $10 \mathrm{~cm} \times 7 \mathrm{~cm} \times$ $0.5 \mathrm{~cm}$ square clear Plexiglas base to prevent mice from moving the objects during testing. 
The familiarization training and the testing trials were videotaped and the time spent exploring each object was determined by a trained observer. 'Exploration' was defined as approaching the object nose-first within $2-4 \mathrm{~cm}$. The time spent exploring each object, as a percentage of the total exploration time, was calculated for each trial. Location novelty recognition was calculated as the difference between the percent time spent exploring the object in the novel location (trial 4) and the percent time spent exploring the same object in its original location on the previous trial (trial 3). The percent time spent exploring the novel object during trial 5 was calculated to measure object novelty recognition.

Two individual experiments were performed using this test. In the first experiment eight 5$\mathrm{HT}_{7}^{+/+}$mice were compared with nine 5- $\mathrm{HT}_{7}{ }^{-/-}$mice. In the second experiment 20 male C57BL/6J mice were tested. After the three habituation trials these mice received a single intraperitoneal injection. Ten mice were administered the selective $5-\mathrm{HT}_{7}$ receptor antagonist SB-269970 (Tocris, Ellisville, MO;) at $10 \mathrm{mg} / \mathrm{kg}$, a dose found to give physiological effects in previous studies [42] and ten mice were administered vehicle ( $0.9 \%$ saline). The testing trials were performed 15 minutes after the injections.

\subsection{Barnes Maze}

A modified Barnes maze was utilized to perform additional spatial memory testing [43]. The maze consisted of an opaque Plexiglas disk $75 \mathrm{~cm}$ in diameter elevated $58 \mathrm{~cm}$ above the floor by a tripod. Twenty holes, $5 \mathrm{~cm}$ in diameter were evenly distributed around the disk, located $5 \mathrm{~cm}$ from the perimeter. A black Plexiglas escape box $(19 \times 8 \times 7 \mathrm{~cm})$ was placed underneath one of the holes. Distinct visual cues were situated around the maze, off the platform and were kept constant throughout the experiment. In this experiment eight $5-\mathrm{HT}_{7}{ }^{+/+}$and eight 5$\mathrm{HT}_{7}^{-/-}$mice were tested.

Before the experiment, a training session was conducted in which the animal to be studied was placed in the escape box undisturbed for one minute immediately preceding the first session. The sessions were initiated by placing the animal in the middle of the maze in a black, $10 \mathrm{~cm}$ high cylindrical start chamber. After 10 seconds the start chamber was removed and an $80 \mathrm{~dB}$ buzzer and a 400 lux light illuminating the maze were turned on. The mouse was allowed to explore the maze for 3 minutes undisturbed. If the escape box was not located within three minutes of free search, the mouse was gently guided into the escape hole where it was allowed to remain for one minute with buzzer and light turned off. The escape box remained in its original position for subsequent sessions. The animals were tested for 12 days with one session per day. The number of sessions was chosen to ensure overtraining and thus most likely a shift in spatial memory strategy from allocentric to egocentric spatial memory in both genotypes. These and subsequent sessions were videotaped and scored by an experimenter blind to the genotype of the mouse. The measurements made for the twelve habituation sessions were time needed to locate the escape box, the distance traveled, and the speed.

A probe test was conducted as the $13^{\text {th }}$ sessions. For the this session, the escape box was removed and the animals were allowed to roam freely in the maze for three minutes and the time spent in the quadrant of the escape box was compared with the average time spent in the other quadrants. This is a direct test for spatial memory in which the animal utilizes off set cues for behavioral decision-making.

One month later, the animals were tested for memory retention (retention test) in a regular setting in which the escape box was located in its original location, allowing for long-term memory examination. The following day a final session was performed in which the escape box was moved to a new location 180 degrees from its original position (reversal test). The reversal test allowed for examination of perseveration at the original hole as well as any working memory strategies the mice had adopted to locate the escape box in its new location. 


\subsection{Neurogenesis}

2.4.1 Bromodeoxyuridine (BrdU) treatment-In order to visualize mitotic cells within the subgranular zone of the dentate gyrus in the hippocampal formation mice were treated with BrdU for three consecutive days twice daily at 09:00 and 11:00. The BrdU (Sigma, St. Louis, MO) was dissolved in $0.9 \%$ saline and administered intraperitoneally in a dose of $50 \mathrm{mg} / \mathrm{kg}$ body weight.

2.4.2 Brain fixation and sectioning-Twenty-four hours after the last BrdU injection, the animals were deeply anesthetized with isoflurane and perfused transcardially with PBS for 20 seconds followed by $4 \%$ paraformaldehyde in PBS for 15 minutes. The brains were quickly resected and submerged in $4 \%$ paraformaldehyde in PBS solution and kept overnight at $4{ }^{\circ} \mathrm{C}$. After overnight fixation the brains were transferred into $30 \%$ sucrose solution in $4 \%$ paraformaldehyde in PBS until the brains were negatively buoyant. At this point the brains were stored at $-80^{\circ} \mathrm{C}$ for later use.

Before sectioning, the frozen brains were allowed to equilibrate in a cryostat apparatus at $-20^{\circ}$ $\mathrm{C}$ for 30 minutes. The brains were sectioned in $25 \mu \mathrm{m}$ coronal slices.

2.4.3 Immunohistochemistry-For BrdU labeling the sections were incubated in 50\% formamide in $2 \times \mathrm{SSC}$ buffer at $65^{\circ} \mathrm{C}$ for 2 hours, followed by a series of PBS washes and a 30 minute incubation in $2 \mathrm{~N} \mathrm{HCl}$ at $37^{\circ} \mathrm{C}$ for antigen retrieval. The $\mathrm{HCl}$ was neutralized by a 10-minute incubation in 0.1 M Sodium Borate. The sections were quenched and blocked for 3 minutes in PBS with 3\% hydrogen peroxide and $0.3 \%$ horse serum followed by several PBS washes. The sections were incubated with avidin for 15 minutes followed by 15 minute incubation with biotin. The sections were washed and native IgG was blocked using mouse IgG blocking solution (M.O.M kit; Vector, Burlingame, CA). Sections were washed and subsequently incubated in primary mouse anti-BrdU antibody (Roche, Indianapolis, IN), at 1:500 dilution in PBS, $2 \%$ BSA and $0.1 \%$ Triton X-100 overnight at $4^{\circ} \mathrm{C}$ with gentle shaking. The sections were washed with PBS, and incubated with biotinylated anti-mouse IgG for 10 minutes. The Vectastain Elite ABC (Vector, Burlingame, $\mathrm{CA}$ ) working solution was added to the tissue and incubated for another 10 minutes. A working DAB solution was prepared in accordance with the manufacturer's protocol (Vector, Burlingame, CA), incubated for 30 minutes at room temperature and added directly to the tissue. After the five minute incubation, the sections were washed with distilled water, rinsed into a dish with PBS containing $0.1 \%$ Triton X-100, mounted on slides, counterstained with hematoxylin for morphological landmark recognition.

2.4.4 Analysis-The tissue was analyzed based on previously published methodology [44]. Briefly, in order to prevent counting the same cell twice every sixth section from each hippocampus was analyzed. The mounted sections were photographed under $20 \mathrm{X}$ magnification and the labeled cells were counted for each animal hippocampus using Image $\mathbf{J}$ software (National Institutes of Health). Based on predefined anatomical landmarks, equal areas at the same rostrocaudal levels where analyzed for each animal.

\subsection{Statistical analysis}

Possible differences between genotypes or treatment groups in novel location and novel object recognition were analyzed using Student's unpaired t-test. As multiple comparisons were made for the same animals all $p$-values were adjusted using Bonferroni correction. The Barnes maze data were analyzed using repeated measures two-way analysis of variance with genotype as one factor and testing session as the other factor. Differences between specific groups were evaluated using a Bonferroni posttest. In the neurogenesis experiment the number of counted cells was compared using Student's unpaired t-test. All analyses were performed using the 
GraphPad Prism (http://www.graphpad.com; GraphPad Software Inc., San Diego, California) software package. Differences were considered significant at $p<0.05$.

\section{Results}

\subsection{Novel location/Novel object recognition}

The data from the novel location/ novel object test were analyzed as previously described $[40,41] .5-\mathrm{HT}_{7}^{-/-}$mice had reduced location novelty recognition compared with $5-\mathrm{HT}_{7}^{+/+}$mice (Fig. 1A). Both 5- $\mathrm{HT}_{7}^{+/+}$and $5-\mathrm{HT}_{7}^{-/-}$showed recognition of the novel object, with no difference between the genotypes (Fig. 1C). Treatment with SB-269970 (10 mg/kg) caused reduced location novelty recognition compared with vehicle-treated mice (Fig. 1B). Both SB-269970 and vehicle-treated mice showed recognition of the novel object, with no difference between the groups (Fig. 1D).

\subsection{Barnes Maze}

Analysis of the acquisition phase (sessions 1-12) of the Barnes maze experiment using repeated measures two-way ANOVA showed a significant effect for session $\left(\mathrm{F}_{(10,140)}=13.36, p<\right.$ $0.0001)$ in the time required to locate the escape box, with no difference between the genotypes (Fig. 2A). A similar effect for session $\left(\mathrm{F}_{(10,140)}=12.47, p<0.0001\right)$ was seen for distance traveled to locate the box (Fig. 2B). As the performance reached a plateau, it was determined that overtraining had been achieved.

The results of the follow-up sessions, performed after the acquisition phase, are summarized in Table 1. In the probe session, in which the escape box had been removed, a significant difference between the genotypes in the time spent in the quadrant where the escape box was originally located was observed. The $5-\mathrm{HT}_{7}{ }^{-/-}$mice repeatedly returned to the original quadrant of the escape box resulting in longer time spent in this quadrant (Table 1).

The retrieval test conducted a month after the probe session showed that both $5-\mathrm{HT}_{7}{ }^{+/+}$and 5$\mathrm{HT}_{7}{ }^{-/-}$mice retained the ability to quickly locate the escape box (Table 1).

The reversal test revealed a marked difference in behavior between the $5-\mathrm{HT}_{7}^{+/+}$and the 5$\mathrm{HT}_{7}^{-/-}$mice. As expected, all animals initially went to the original location of the escape box, resulting in an apparent overall increase in the time need to locate the escape box (Table 1). However, once the now empty hole had been encountered, $5-\mathrm{HT}_{7}{ }^{+/+}$mice began searching for the escape box elsewhere. The 5- $\mathrm{HT}_{7}^{-/-}$mice, on the other hand, exhibited a pronounced perseverance in searching for the box at its original location as seen from repeated returns to the empty hole. Overall, there was no difference between the genotypes in the time needed to locate the escape box, but the $5-\mathrm{HT}_{7}^{-/-}$mice spent more time in the quadrant where the box had originally been located, (Table 1).

\subsection{Neurogenesis}

The rate of neurogenesis was assessed by counting the number of cells incorporating 5'bromo-2'-deoxyuridine (BrdU) in the subgranular zone of the dentate gyrus. BrdU is a thymidine analog that incorporates into dividing cells during DNA synthesis. Once incorporated into the new DNA, BrdU will remain in place and be passed down to daughter cells following mitosis.

The objective of the experiment was to assess if there was an overall difference in the number of proliferating cells between $5-\mathrm{HT}_{7}{ }^{+/+}$and $5-\mathrm{HT}_{7}{ }^{-/-}$mice. As such, no attempt was made to quantify the total number of dividing cells in each animal, but every attempt was made to analyze equal areas at equal rostrocaudal levels for each animals. The number of BrdU positive 
cells was counted in on average 40 coronal sections for each animal. Due to a certain amount of tissue loss during sectioning the values for a few animals had to be adjusted by extrapolation. Thus, the number of BrdU-positive cells counted was $1015 \pm 72$ for $5-\mathrm{HT}_{7}{ }^{+/+}$mice and 1012 \pm 92 for $5-\mathrm{HT}_{7}{ }^{-/}$-mice, suggesting that hippocampal neurogenesis (cell proliferation) is not altered in $5-\mathrm{HT}_{7}^{-/-}$mice.

\section{Discussion}

The main finding of the present study was that manipulations of the $5-\mathrm{HT}_{7}$ receptor induced changes in particular aspects of memory based on spatial cues. Even though the observed changes most likely involve the hippocampus, the study furthermore showed that the changes probably did not involve hippocampal cell proliferation, but possibly cell differentiation and synaptic plasticity. As shown in both the novel location test and the Barnes maze, animals lacking the $5-\mathrm{HT}_{7}$ receptor exhibited reduced sensitivity to spatial changes in their environment compared to their wild-type siblings.

Both $5-\mathrm{HT}_{7}^{+/+}$and $5-\mathrm{HT}_{7}^{-/-}$mice showed expected habituation in the novel location/novel object experiment. However, in the novel location session it was found that the $5-\mathrm{HT}_{7}{ }^{-1-}$ mice were indifferent to spatial changes in their environment in comparison with the $5-\mathrm{HT}_{7}^{+/+}$mice. A similar effect could be induced in C57BL/6J mice with the selective 5- $\mathrm{HT}_{7}$ receptor antagonist SB-269970. The finding that both genetic inactivation and pharmacological blockade of the $5-\mathrm{HT}_{7}$ receptor yield the same result strongly supports an involvement of the $5-\mathrm{HT}_{7}$ receptor. Support for such an involvement is further reinforced by our previous conclusion that observations made in the $5-\mathrm{HT}_{7}{ }^{-/}$mice reflect $5-\mathrm{HT}_{7}$ receptor function. A similar correlation to the one observed in the present study between inactivation and blockade of the $5-\mathrm{HT}_{7}$ receptor has been seen in studies on thermoregulation $[38,45]$ and in behavioral models of depression [42].

The novel location and novel object tests consist of both hippocampus-dependent and independent parts. It has previously been shown that the ability to recognize novel objects in the environment is unaltered by hippocampal lesions [46,40], whereas location novelty recognition is. Therefore, this test is particularly useful in determining hippocampus-specific cognitive differences. Thus, a direct involvement of the hippocampus in the observed behavioral phenotype is likely since novel object recognition was not affected. Both 5$\mathrm{HT}_{7}^{+/+}$and $5-\mathrm{HT}_{7}^{-/-}$mice performed with comparable object novelty recognition, as did vehicle and SB-269970 treated mice.

It is unlikely that the findings from the novel location test (and the Barnes maze discussed below) were due to differences in visual perception between the genotypes as a previous study using a visual cliff test showed that $5-\mathrm{HT}_{7}{ }^{-/}$mice have unaltered visual acuity [32] suggesting that the $5-\mathrm{HT}_{7}$ receptor does not influence the activity of the inferotemporal area of the cortex which is critical for visual recognition [47].

The Barnes maze test showed that the $5-\mathrm{HT}_{7}{ }^{-/-}$mice performed virtually identically to their 5$\mathrm{HT}_{7}^{+/+}$siblings during the initial 12 sessions. This finding indicates that the $5-\mathrm{HT}_{7}^{-/-}$mice did not exhibit learning impairments and/or dysfunctions in short-term memory if the environment remains static. In the same test, the relative distance traveled by both genotypes is in accordance with the time required to locate the escape box and thus the calculated relative speed for either genotype did not change considerably throughout the experiment, confirming that the differences observed in 5- $\mathrm{HT}_{7}^{-/-}$mice cannot be attributed to differences in locomotor activity. The lack of locomotor impairments in $5-\mathrm{HT}_{7}^{-/-}$mice was also previously shown in an open arena test conducted over a 24 hour period [32]. 
The Barnes maze retention test showed that the $5-\mathrm{HT}_{7}^{-/-}$mice have no impairments in longterm memory and memory consolidation compared with their wild-type siblings. Both genotypes were able to efficiently retain the ability to locate the escape box during the retention test.

The data from the reversal test mimicked the results obtained from the probe test as the 5$\mathrm{HT}_{7}^{+/+}$mice in both tests spent significantly less time in the original quadrant of the escape box. The generally observed behavior was that $5-\mathrm{HT}_{7}^{+/+}$and $5-\mathrm{HT}_{7}{ }^{-/-}$initially follow a direct path towards the presumed position of the escape box for sessions 12, probe, reversal, and retention. Thus, it can be hypothesized that both genotypes learn the route to the escape box, whereas there is a genotypic difference in which the $5-\mathrm{HT}_{7}{ }^{+/+}$mice form a more dynamic association between the route and the placement of the escape box while the $5-\mathrm{HT}_{7}^{-/ /}$mice more rigidly link the two as was seen in the probe and reversal tests. When the $5-\mathrm{HT}_{7}{ }^{-/-}$mice reached the empty escape hole during the reversal and the probe tests they began exploring the maze, but when they happened to pass the vicinity of the starting position, these mice took the initial route back to the empty escape box. A possible explanation for this type of behavior is the reliance on a mainly striatum-dependent, egocentric memory formed as a result of overtraining and characterized by a passive form of information processing. It is reasonable to assume that striatum-dependent egocentric memory is spared in $5-\mathrm{HT}_{7}{ }^{-/-}$mice because of the low abundance of $5-\mathrm{HT}_{7}$ receptors in this area [28]. The $5-\mathrm{HT}_{7}{ }^{+/+}$mice in contrast exhibited less backtracking compared with the $5-\mathrm{HT}_{7}^{-/-}$mice. Thus, their search strategy most likely involved a more continuous and active information processing that included triangulation and dynamic reference memory, which in turn likely translates into greater hippocampusdependent allocentricity in the spatial memory $[7,48]$. Anatomically it has been demonstrated that the 5- $\mathrm{HT}_{7}$ receptor is present in all parts of the hippocampus [28]. Interestingly, the highest densities were observed in the $\mathrm{CA} 3$ region and the dentate gyrus, regions of the hippocampus which have been shown to be involved in the response to changes in the environment [51, 52].

The present results suggest that the $5-\mathrm{HT}_{7}$ receptor is not involved in short-term and long-term memory formation, memory consolidation, and memory retrieval. It can also be concluded that this receptor does not play a significant role in striatum-dependent egocentric spatial memory. However, it appears that the switch form a striatal strategy towards hippocampus-dependent allocentric memory is impaired in $5-\mathrm{HT}_{7}^{-/-}$mice. The $5-\mathrm{HT}_{7}$ receptor might be important in the formation of associations with the network of memories and the compilation and correlation of these memories with changes in the environment. In other words, having the ability to make comparative analyses of the network of surrounding objects with the virtual network (memory network) created by a test subject regarding its environment.

The present Barnes maze test results may appear to be in contrast with results previously obtained in a Barnes maze test that was conducted using the same knockout strain of mice [32]. In the previous experiment the end of a session was marked by the animal actually entering the escape box or after five minute elapsed, whereas in the current work the sessions were considered successfully completed once the animal had made a head dip into the hole containing the escape box or after three minute elapsed. As a memory test we considered that approaching the escape hole better reflects memory of its location then actual entrance into the escape box while better excluding other factors such as curiosity and explorative instincts.

Additionally, the previous study included 40 consecutive trials as opposed to 12 sessions in the current work.

It has previously been suggested that the rate of neurogenesis in the hippocampus is linked with memory consolidation and spatial learning [59]. As we found no difference in the number of cells that had incorporated BrdU between $5-\mathrm{HT}_{7}^{+/+}$and $5-\mathrm{HT}_{7}^{-/-}$mice it may be speculated 
that the $5-\mathrm{HT}_{7}$ receptor is involved in cell differentiation and/or synaptic plasticity and dendritic rearrangement rather then cell proliferation. It should be noted that the $5-\mathrm{HT}_{7}{ }^{-{ }_{-}}$mice do not exhibit impairments in learning (Barnes maze sessions 1-12), memory consolidation, and retrieval (Barnes maze retention test).

In conclusion, the present study has shown that the $5-\mathrm{HT}_{7}$ receptor is of importance for allocentric spatial memory. More specifically, the data suggest that this receptor might be involved in the retention of information and in the activation of hippocampus-dependent memory processes when it becomes necessary to switch from striatum-dependent memory processing [49]. The 5- $\mathrm{HT}_{7}$ receptor appears to be less involved in learning, memory consolidation, and memory retrieval. Furthermore, the $5-\mathrm{HT}_{7}$ receptor is not involved in egocentric spatial memory. It was also shown that cell proliferation in the dentate gyrus is not altered by inactivation of the $5-\mathrm{HT}_{7}$ receptor. As the $5-\mathrm{HT}_{7}$ receptor has been suggested as a putative target for the treatment of certain neuropsychiatric disorders, its role in memory functions must be taken into consideration when evaluating any such treatments.

\section{Acknowledgments}

This work was supported by NIMH grant MH73923. We wish to thank Patria Danielson for excellent technical assistance. We also wish to thank the Mouse Behavioral Assessment Core Facility at The Scripps Research Institute and its director Amanda Roberts for their assistance.

\section{References}

1. Schon, K.; Quiroz, YT.; Hasselmo, ME.; Stern, CE. Greater Working Memory Load Results in Greater Medial Temporal Activity at Retrieval [Internet]. Cereb Cortex. 2009. ; [cited 2009 Mar 3 ] Available from: http://www.ncbi.nlm.nih.gov/pubmed/19224975

2. Milner B, Johnsrude I, Crane J. Right medial temporal-lobe contribution to object-location memory. Philos Trans R Soc Lond B Biol Sci 1997;1360:1469-1474. [PubMed: 9368935]

3. Nadel L, Moscovitch M. Memory consolidation, retrograde amnesia and the hippocampal complex. Curr Opin Neurobiol 1997;2:217-227. [PubMed: 9142752]

4. Jonides J, Smith EE, Koeppe RA, Awh E, Minoshima S, Mintun MA. Spatial working memory in humans as revealed by PET. Nature 1993;6430:623-625. [PubMed: 8510752]

5. Zarahn E, Aguirre GK, D'Esposito M. Temporal isolation of the neural correlates of spatial mnemonic processing with fMRI. Brain Res Cogn Brain Res 1999;3:255-68. [PubMed: 9838152]

6. Stein JF. Representation of egocentric space in the posterior parietal cortex. Q J Exp Physiol 1989;5:583-606. [PubMed: 2687924]

7. Berke JD, Breck JT, Eichenbaum H. Striatal versus hippocampal representations during win-stay maze performance. J Neurophysiol 2009;3:1575-87. [PubMed: 19144741]

8. Schultz W, Romo R. Role of primate basal ganglia and frontal cortex in the internal generation of movements. I. Preparatory activity in the anterior striatum. Exp Brain Res 1992;3:363-84. [PubMed: 1483512]

9. Berke JD. Uncoordinated firing rate changes of striatal fast-spiking interneurons during behavioral task performance. J Neurosci 2008;40:10075-80. [PubMed: 18829965]

10. Schacter, D.; Nadel, L. Varieties of spatial memory: a problem for cognitive neuroscience. In: Lister, RG.; Weingartner, HJ., editors. Perspectives on cognitive neuroscience. New York: Oxford University Press; 1991. p. 165-185.

11. Holdstock JS, Mayes AR, Cezayirli E, Isaac CL, Aggleton JP, Roberts N. A comparison of egocentric and allocentric spatial memory in a patient with selective hippocampal damage. Neuropsychologia 2000;4:410-425. [PubMed: 10683392]

12. Brasted PJ, Humby T, Dunnett SB, Robbins TW. Unilateral lesions of the dorsal striatum in rats disrupt responding in egocentric space. J Neurosci 1997;22:8919-26. [PubMed: 9348358]

13. Cook D, Kesner RP. Caudate nucleus and memory for egocentric localization. Behav Neural Biol 1988;3:332-43. [PubMed: 3408445] 
14. Morris RG, Garrud P, Rawlins JN, O'Keefe J. Place navigation impaired in rats with hippocampal lesions. Nature 1982;5868:681-683. [PubMed: 7088155]

15. Eichenbaum H. A cortical-hippocampal system for declarative memory. Nat Rev Neurosci 2000;1:41-50. [PubMed: 11252767]

16. Kesner RP, Novak JM. Serial position curve in rats: role of the dorsal hippocampus. Science 1982;4568:173-175. [PubMed: 7123228]

17. Eichenbaum H, Stewart C, Morris RG. Hippocampal representation in place learning. J Neurosci 1990;11:3531-3542. [PubMed: 2230943]

18. Maren S. Building and burying fear memories in the brain. Neuroscientist 2005;1:89-99. [PubMed: 15632281]

19. Sacchetti B, Lorenzini CA, Baldi E, Bucherelli C, Roberto M, Tassoni G, Brunelli M. Time-dependent inhibition of hippocampal LTP in vitro following contextual fear conditioning in the rat. Eur J Neurosci 2002;1:143-150. [PubMed: 11860514]

20. Shors TJ, Seib TB, Levine S, Thompson RF. Inescapable versus escapable shock modulates longterm potentiation in the rat hippocampus. Science 1989;4901:224-226. [PubMed: 2704997]

21. Eichenbaum H. Declarative memory: insights from cognitive neurobiology. Annu Rev Psychol 1997:547-572. [PubMed: 9046568]

22. Scoville WB, Milner B. Loss of recent memory after bilateral hippocampal lesions. J Neurol Neurosurg Psychiatry 1957;1:11-21. [PubMed: 13406589]

23. Corkin S. Lasting consequences of bilateral medial temporal lobectomy: Clinical course and experimental findings. HM Sem Neurol 1984:249-259.

24. Squire LR, Knowlton B, Musen G. The structure and organization of memory. Annu Rev Psychol 1993:453-495. [PubMed: 8434894]

25. Zhong P, Liu W, Gu Z, Yan Z. Serotonin facilitates long-term depression induction in prefrontal cortex via p38 MAPK/Rab5-mediated enhancement of AMPA receptor internalization. J Physiol 2008;(Pt 18):4465-79. [PubMed: 18653660]

26. Abe K, Fujimoto T, Akaishi T, Misawa M. Stimulation of basolateral amygdaloid serotonin 5-HT (2C) receptors promotes the induction of long-term potentiation in the dentate gyrus of anesthetized rats. Neurosci Lett 2009;1:65-8. [PubMed: 19110035]

27. Hoyer D, Hannon JP, Martin GR. Molecular, pharmacological and functional diversity of 5-HT receptors. Pharmacol Biochem Behav 2002;4:533-554. [PubMed: 11888546]

28. Bonaventure P, Nepomuceno D, Hein L, Sutcliffe JG, Lovenberg T, Hedlund PB. Radioligand binding analysis of knockout mice reveals 5-hydroxytryptamine(7) receptor distribution and uncovers 8hydroxy-2-(di-n-propylamino)tetralin interaction with alpha(2) adrenergic receptors. Neuroscience 2004;4:901-911. [PubMed: 15026130]

29. Plassat JL, Amlaiky N, Hen R. Molecular cloning of a mammalian serotonin receptor that activates adenylate cyclase. Mol Pharmacol 1993;2:229-236. [PubMed: 8394987]

30. Martín-Cora FJ, Pazos A. Autoradiographic distribution of 5-HT7 receptors in the human brain using [3H]mesulergine: comparison to other mammalian species. Br J Pharmacol 2004;1:92-104.

31. Hedlund P, Sutcliffe G. Functional, molecular and pharmacological advances in 5-HT7 receptor research. Trends Pharmacol Sci 2004;9:481-486. [PubMed: 15559250]

32. Roberts A, Krucker T, Levy CL, Slanina KA, Sutcliffe JG, Hedlund PB. Mice lacking 5-HT receptors show specific impairments in contextual learning. Eur J Neurosci 2004;7:1913-1922. [PubMed: 15078565]

33. Gasbarri A, Cifariello A, Pompili A, Meneses A. Effect of 5-HT(7) antagonist SB-269970 in the modulation of working and reference memory in the rat. Behav Brain Res 2008;1:164-170. [PubMed: 18308404]

34. Markakis EA, Gage FH. Adult-generated neurons in the dentate gyrus send axonal projections to field CA3 and are surrounded by synaptic vesicles. J Comp Neurol 1999;4:449-460. [PubMed: 10205022]

35. Barnea A, Nottebohm F. Seasonal recruitment of hippocampal neurons in adult free-ranging blackcapped chickadees. Proc Natl Acad Sci USA 1994;23:11217-11221. [PubMed: 7972037]

36. Kempermann G. Why new neurons? Possible functions for adult hippocampal neurogenesis. J Neurosci 2002;3:635-638. [PubMed: 11826092] 
37. Buhot MC, Martin S, Segu L. Role of serotonin in memory impairment. Ann Med 2000;3:210-221. [PubMed: 10821328]

38. Hedlund P, Danielson P, Thomas EA, Slanina K, Carson MJ, Sutcliffe JG. No hypothermic response to serotonin in 5-HT7 receptor knockout mice. Proc Natl Acad Sci USA 2003;3:1375-1380.

[PubMed: 12529502]

39. Cowen DS, Takase LF, Fornal CA, Jacobs BL. Age-dependent decline in hippocampal neurogenesis is not altered by chronic treatment with fluoxetine. Brain Res 2008:14-19. [PubMed: 18616933]

40. Benice, Raber. Object recognition analysis in mice using nose-point digital video tracking. J Neurosc Met 2008;2:422-430.

41. Benice TS, Rizk A, Kohama S, Pfankuch T, Raber J. Sex-differences in age-related cognitive decline in C57BL/6J mice associated with increased brain microtubule-associated protein 2 and synaptophysin immunoreactivity. Neurosci 2006;2:413-423.

42. Hedlund P, Huitron-Resendiz S, Henriksen SJ, Sutcliffe JG. 5-HT7 receptor inhibition and inactivation induce antidepressantlike behavior and sleep pattern. Biol Psychiatry 2005;10:831-837. [PubMed: 16018977]

43. Barnes CA. Memory deficits associated with senescence: a neurophysiological and behavioral study in the rat. J Comp Physiol Psychol 1979;1:74-104. [PubMed: 221551]

44. Malberg JE, Eisch AJ, Nestler EJ, Duman RS. Chronic antidepressant treatment increases neurogenesis in adult rat hippocampus. J Neurosci 2000;24:9104-10. [PubMed: 11124987]

45. Hedlund P, Kelly L, Mazur C, Lovenberg T, Sutcliffe JG, Bonaventure P. 8-OH-DPAT acts on both 5-HT1A and 5-HT7 receptors to induce hypothermia in rodents. Eur J Pharmacol 2004;1-3:125-132. [PubMed: 15033384]

46. Ennaceur A, Neave N, Aggleton JP. Spontaneous object recognition and object location memory in rats: the effects of lesions in the cingulate cortices, the medial prefrontal cortex, the cingulum bundle and the fornix. Exp Brain Res 1997;3:509-519. [PubMed: 9108217]

47. Buffalo EA, Ramus SJ, Clark RE, Teng E, Squire LR, Zola SM. Dissociation between the effects of damage to perirhinal cortex and area TE. Learn Mem 1999;6:572-599. [PubMed: 10641763]

48. Sanders AE, Holtzer R, Lipton RB, Hall C, Verghese J. Egocentric and exocentric navigation skills in older adults. J Gerontol A Biol Sci Med Sci 2008;12:1356-63. [PubMed: 19126849]

49. Packard MG, McGaugh JL. Inactivation of hippocampus or caudate nucleus with lidocaine differentially affects expression of place and response learning. Neurobiol Learn Mem 1996;1:6572. [PubMed: 8673408]

50. Maguire EA, Burgess N, Donnett JG, Frackowiak RS, Frith CD, O'Keefe J. Knowing where and getting there: a human navigation network. Science 1998;5365:921-4. [PubMed: 9572740]

51. Goodrich-Hunsaker NJ, Hunsaker MR, Kesner RP. The interactions and dissociations of the dorsal hippocampus subregions: how the dentate gyrus, CA3, and CA1 process spatial information. Behav Neurosci 2008;1:16-26. [PubMed: 18298245]

52. Hunsaker MR, Rosenberg JS, Kesner RP. The role of the dentate gyrus, CA3a,b, and CA3c for detecting spatial and environmental novelty. Hippocampus 2008;10:1064-73. [PubMed: 18651615]

53. Ambrogini P, Cuppini R, Cuppini C, Ciaroni S, Cecchini T, Ferri P, Sartini S, Del Grande P. Spatial learning affects immature granule cell survival in adult rat dentate gyrus. Neurosci Lett 2000;1:214. [PubMed: 10822143] 

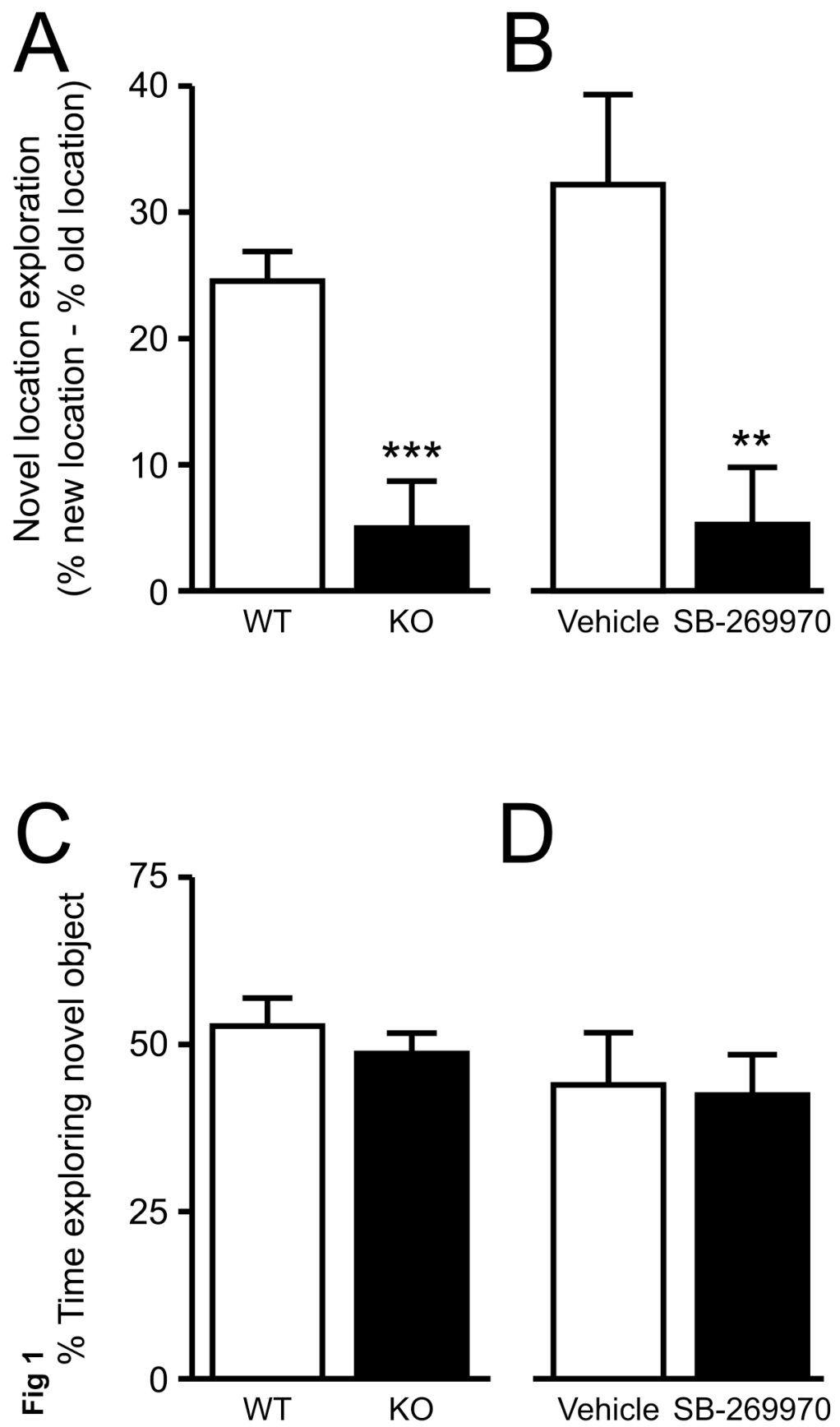

FIGURE 1.

Location and object novelty recognition. (A) $5-\mathrm{HT}_{7}^{-/-}(\cdot, \mathrm{KO})$ mice showed reduced location novelty recognition compared with $5-\mathrm{HT}_{7}{ }^{+/+}(\square, \mathrm{WT})$ mice. (B) Male C57BL/6J ( $\square$ ) mice treated with SB-269970 $(10 \mathrm{mg} / \mathrm{kg})$ showed reduced location novelty recognition compared with vehicle (*) treated mice. (C, D) All mice tested showed object novelty recognition. Values are mean \pm SEM. $\mathrm{n}=9$ for $5-\mathrm{HT}_{7}^{+/+}$and 8 for $5-\mathrm{HT}_{7}{ }^{-/-}$in $\mathrm{A}$ and $\mathrm{C} . \mathrm{n}=10$ per group in $\mathrm{B}$ and D. $* * * p<0.001, * * p<0.01$, Student's t-test with Bonferroni correction for multiple comparisons between the genotypes or treatment groups. 


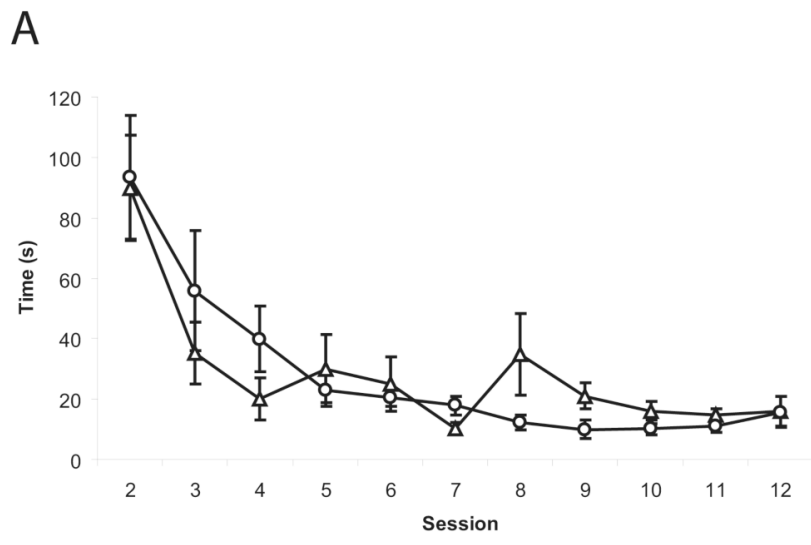

B

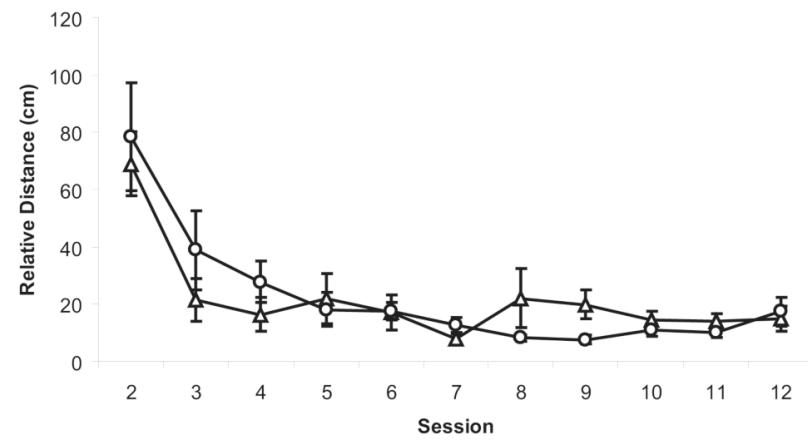

C

$$
2.0
$$

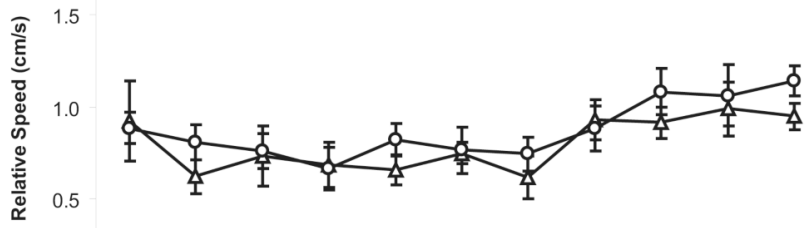

0.0

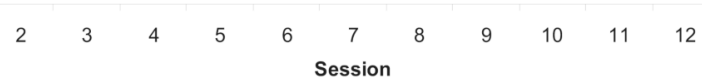

FIGURE 2.

Barnes maze test performed with $5-\mathrm{HT}_{7}{ }^{+/+}(\Delta)$ and $5-\mathrm{HT}_{7}^{-/-}(\circ)$ mice. (A) Logarithmic decrease in time needed to locate the escape box with no difference in the time between $5-\mathrm{HT}_{7}^{+/+}$and $5-\mathrm{HT}_{7}^{-/}$- mice throughout the experiment. (B) The relative distance traveled in order to locate the escape box. (C) Relative speed of $5-\mathrm{HT}_{7}{ }^{+/+}$and $5-\mathrm{HT}_{7}{ }^{-/-}$mice. Values are mean \pm SEM. $\mathrm{n}=8$ per genotype. 
Table 1

Follow-up tests after acquisition training in the Barnes maze.

\begin{tabular}{|c|c|c|c|c|}
\hline \multirow[t]{2}{*}{ Session } & \multicolumn{2}{|c|}{ Time to locate (s) } & \multicolumn{2}{|c|}{ Time in original quadrant (s) } \\
\hline & $5-\mathrm{HT}_{7}^{+/+}$ & $5-\mathrm{HT}_{7}^{-/-}$ & $5-\mathrm{HT}_{7}^{+/+}$ & $5-\mathrm{HT}_{7}^{-/-}$ \\
\hline Probe & N/A & N/A & $67.88 \pm 2.34$ & $90.63 \pm 5.63^{* *}$ \\
\hline Retention & $16.75 \pm 3.68$ & $18.00 \pm 6.50$ & N/A & N/A \\
\hline Reversal & $30.88 \pm 15.22$ & $41.75 \pm 11.39$ & $4.83 \pm 2.24$ & $24.7 \pm 6.24^{*}$ \\
\hline
\end{tabular}

After twelve training sessions the mice were tested in a probe session the following day. In this session the escape box had been removed and the time spent in the quadrant of the maze where the box had originally been located was measured. A month later a normal session was performed (retention) in which the time to locate the escape box was determined. The next day a reversal session was performed where the escape box had been moved 180 degrees. Values are mean \pm SEM. $n=8$ per genotype. N/A, not applicable;

**

$p<0.01$

$p<0.05$,

Student's t-test with Bonferroni correction for multiple comparisons between the genotypes. 